\title{
RESEÑA
}

\section{Simposio Internacional de Historia de la Masonería y los Movimientos Asociativos Latinoamericanos y Caribeños: Prácticas asociativas $y$ Modernidad, siglos XVIII-XXI (San José, Universidad de Costa Rica, 2015)}

\section{Esteban Rodríguez-Dobles}

Maestría en Historia, Universidad de Costa Rica. Profesor de Historia de la Cultura, Escuela de Estudios Generales, Universidad de Costa Rica. Correo electrónico: erdobles@gmail.com

DOI: http://dx.doi.org/10.15517/rehmlac.v7i2.22769

Fecha de recibido: 18 de octubre de 2015 - Fecha de aceptación: 3 de noviembre de 2015

He escrito esta reseña del $I V$ Simposio Internacional de Historia de la Masonería a petición del cuerpo editorial de REHMLAC+, lo cual me pone quizá en un lugar ventajoso a la hora de hacer mis observaciones, quisiera que el lector pudiese encontrar en la presente reseña la apertura a un diálogo sobre nuestras perspectivas de estudio, de ninguna manera una narración definitiva del acontecer, espero que la misma sirva para abrir un debate más amplio.

En primera instancia habría que señalar que la organización de un simposio o actividad similar sobre Historia de la Masonería exige dar pasos muy firmes pues con facilidad las personas, incluso colegas historiadores pueden desvirtuar la actividad académica, malentendiéndose o calificando la actividad de convención masónica y convertir en otra cosa lo que en realidad busca ser un espacio académico que proporciona herramientas interpretativas ante el fenómeno del asociacionismo moderno, estudios de caso, talleres sobre prosopografía, etc. Así el trabajo de divulgación debe ser llevado con especial cuidado y de ser necesario pecar de reiterativo a la hora de señalar el posicionamiento de la actividad en cuestión.

Mis jóvenes estudiantes se sorprendían y miraban con reserva las actividades que les proponía realizar en el marco del simposio, posteriormente sus informes me terminaron de confirmar lo que sospechaba, las actividades ayudaron a la desmitificación, al entendimiento de que existe una comunidad de investigadores que tienen por objeto de estudio la Masonería y a los masones; pero también los había que tituló su trabajo como "Congreso de Masonería". No podemos pasar por alto el halo de misterio que ha rodeado al tema, es parte de las situaciones con las que tenemos que lidiar y hacer nuestro trabajo.

Para quienes estábamos en Costa Rica con la organización de las actividades el Simposio hacía muchas semanas antes que había iniciado. El domingo 1 de Noviembre estaba en el aeropuerto Juan Santamaría recibiendo a uno de nuestros primeros invitados 
el Dr. Juan Pablo Bubello profesor de la Universidad de Buenos Aires, Argentina y director de Centro de Estudios del Esoterismo Occidental/UNASUR. Él impartió un Seminario cuyo tema (el Esoterismo Occidental) se ofrecía por primera vez en nuestra alma mater. Las tres sesiones realizadas en el auditorio de la Biblioteca de Ciencias de la Salud tuvieron una muy buena afluencia de estudiantes, profesores y gente interesada en la temática.

El profesor Bubello es una de las personas que ha hecho eco en el cono sur con sus estudios desde la línea metodológica y conceptual planteada por Antoine Faivre en el año 1986. En la primera sesión tras realizar una arqueología de las concepciones sobre la magia, abarcando perspectivas antropológicas, sociológicas, históricas, estableció 4 de los elementos necesarios para emprender el estudio del esoterismo occidental: 1. El principio de correspondencias, 2. El principio de la naturaleza viva, 3. La mediación entre planos de la existencia, y 4. La experiencia de transmutación de la naturaleza.

\section{Imágenes 1 y 2}

Asistencia a la primera sesión del Seminario: Derivaciones del Esoterismo Occidental en América Latina. Impartido por el Dr. Juan Pablo Bubello. Auditorio de la Biblioteca de Ciencias de la Salud, Universidad de Costa Rica

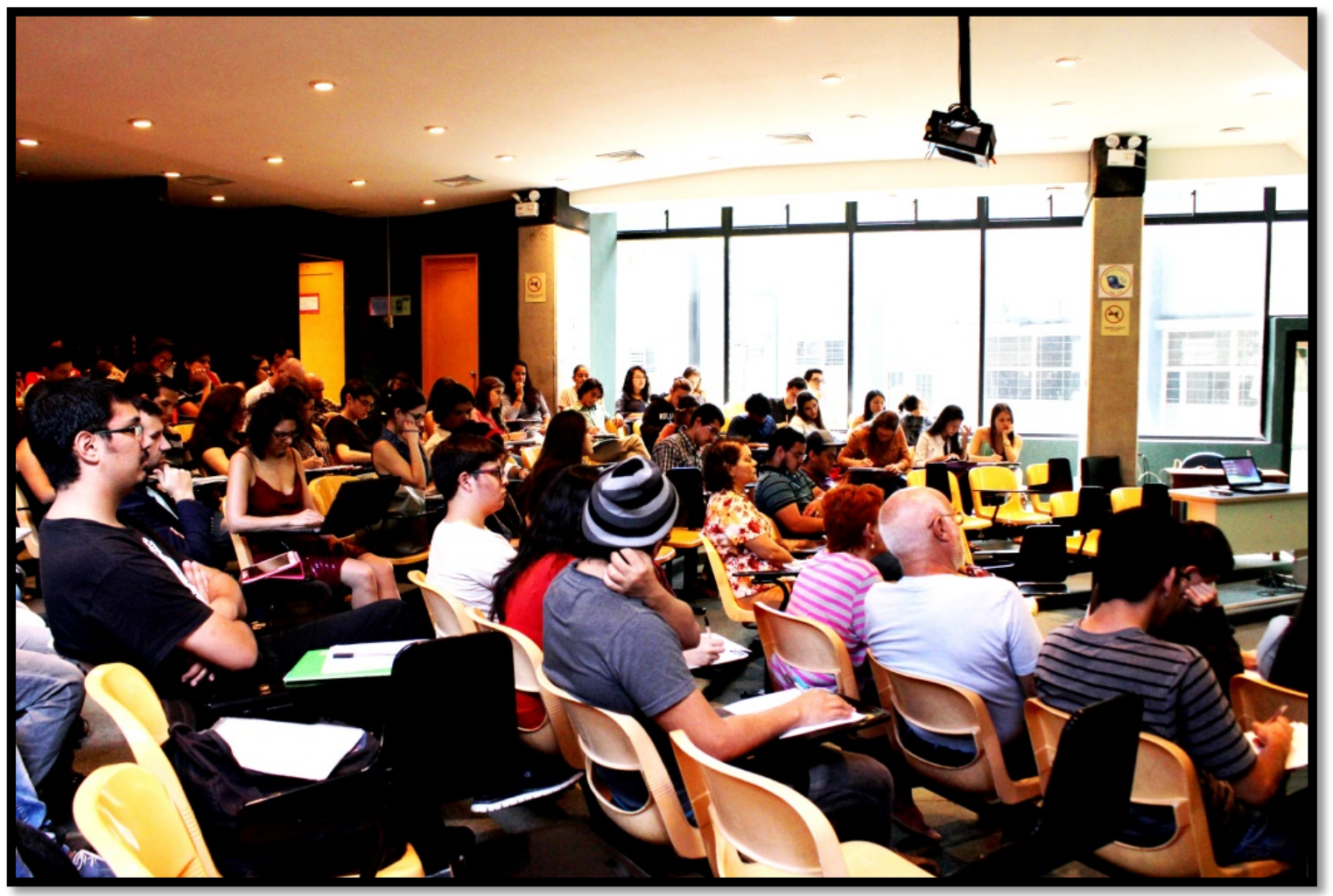




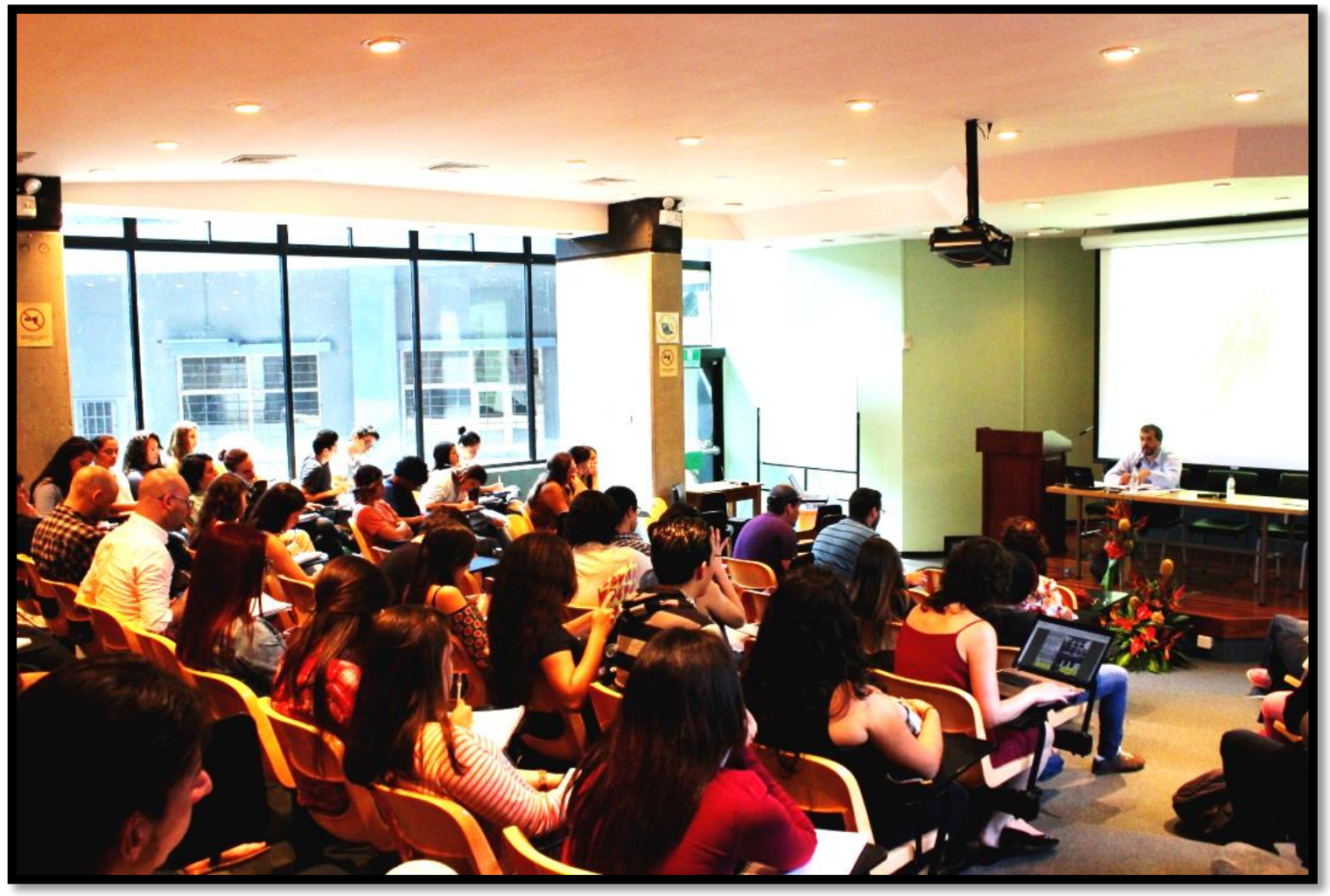

Fotos: Esteban Rodríguez-Dobles

También en esa primera sesión el Dr. Bubello acotó que su abordaje desde la historia cultural partía del conflicto y las conflictividades producto de choques entre mundos representacionales. Este asunto es algo que quiero destacar desde el inicio, pues mi pretensión es hacer visible, el hecho de que el conflicto se ha convertido en la situación predilecta para los historiadores de la contemporaneidad y concretamente los estudiosos de la historia de la masonería, quienes han encontrado una cantera maravillosa tomando materiales de los conflictos para cimentar su relato. O bien podría decirse, el conflicto es el gran escenario para los historiadores de la masonería y esto tiene que ver con la Modernidad misma. Voy a dejar esta idea por un momento, con el propósito de avanzar sobre otros aspectos a cubrir por la presente reseña.

El martes 3 de noviembre, fue la primera sesión del taller impartido por el Dr. Eduardo Madrigal, profesor de la Universidad de Costa Rica. En el mismo el Dr. Madrigal proveyó en primera instancia un recorrido historiográfico para entender la circunscripción de los estudios prosopográficos, y de cultura asociativa. El taller llevó por nombre "Prosopografía, redes de sociabilidad y cultura asociativa en los siglo XVIII-XIX" se desarrolló en el aula 206 de la Facultad de Ciencias Sociales. La concurrencia estuvo compuesta tanto por estudiantes de la UCR como por algunos de los profesores que nos visitaron desde el extranjero, de manera que la asistencia al taller fue internacional, la Habana, Évora, Islas Canarias, Zaragoza, Syracuse, Alajuela, Desamparados, Heredia, etc. 
La prosopografía ha sido una de las técnicas de investigación más utilizada y discutida como instrumento para el estudio de agrupaciones sociales, es decir, que es un esfuerzo por captar una biografía colectiva de un determinado conglomerado social. Para el estudio de estas sociabilidades modernas, la prosopografía ha sido especialmente fértil. Los trabajos del periodo colonial desarrollados por el profesor Madrigal tienen la potencia de captar otras dinámicas del poder en las tierras de ultramar.

Para las horas de la tarde quedó reservado el Coloquio de jóvenes investigadores, profesores de una trayectoria extensa departieron con varias generaciones de estudiosos que empiezan sus caminos como académicos de las Ciencias Sociales. Entre los que se puede acotar la presencia de Dévrig Mólles, Felipe de Solar, Ricardo Martínez, Yván Pozuelo, María Zozaya, Valeria Aguiar, y los maestros José Antonio Ferrer, Eduardo Torres-Cuevas y Miguel Guzmán-Stein.

\section{Imágenes 3 y 4}

Taller de Prosopografía: Dr. Eduardo Madrigal. Coloquio con jóvenes investigadores. Facultad de Ciencias Sociales, Universidad de Costa Rica

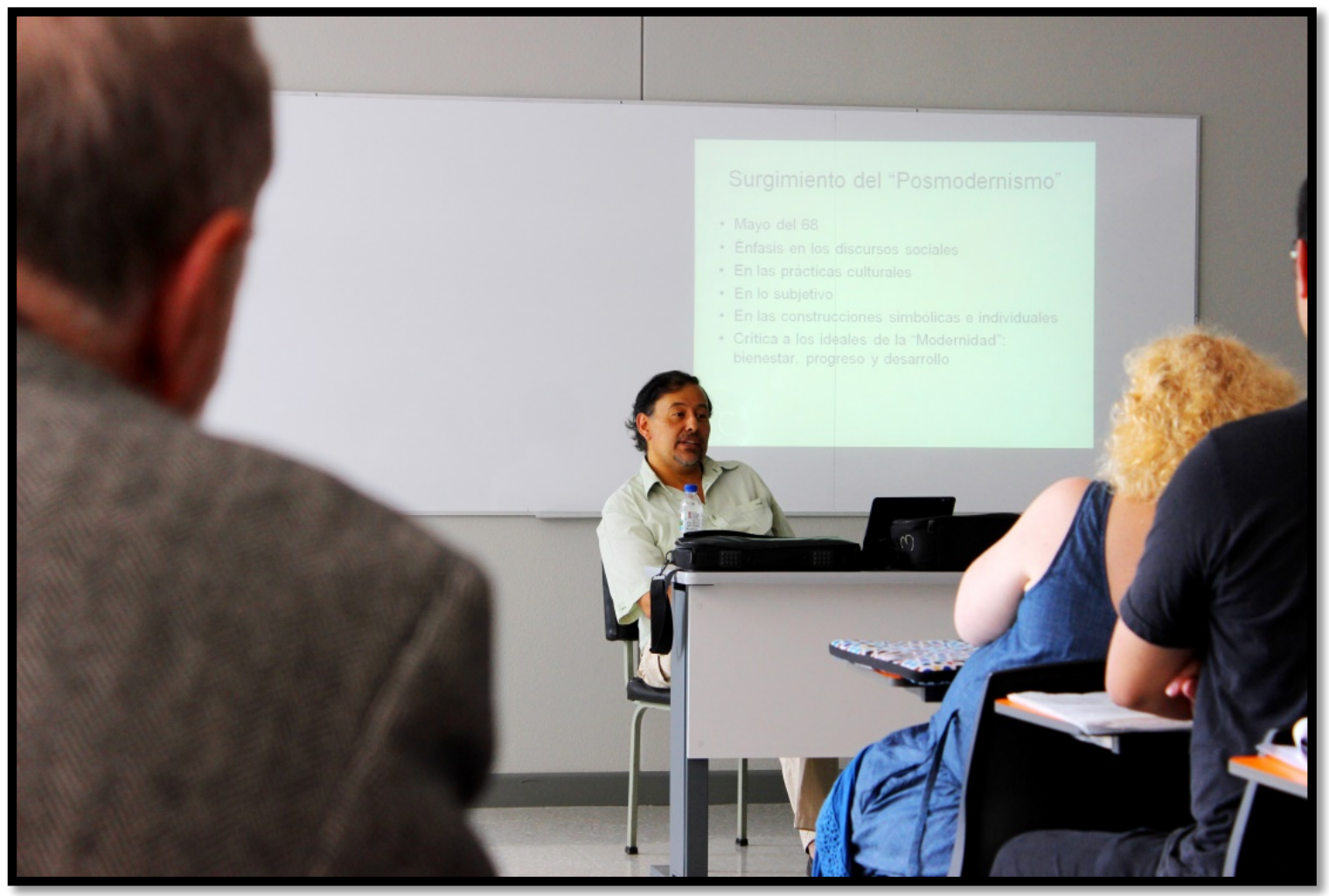




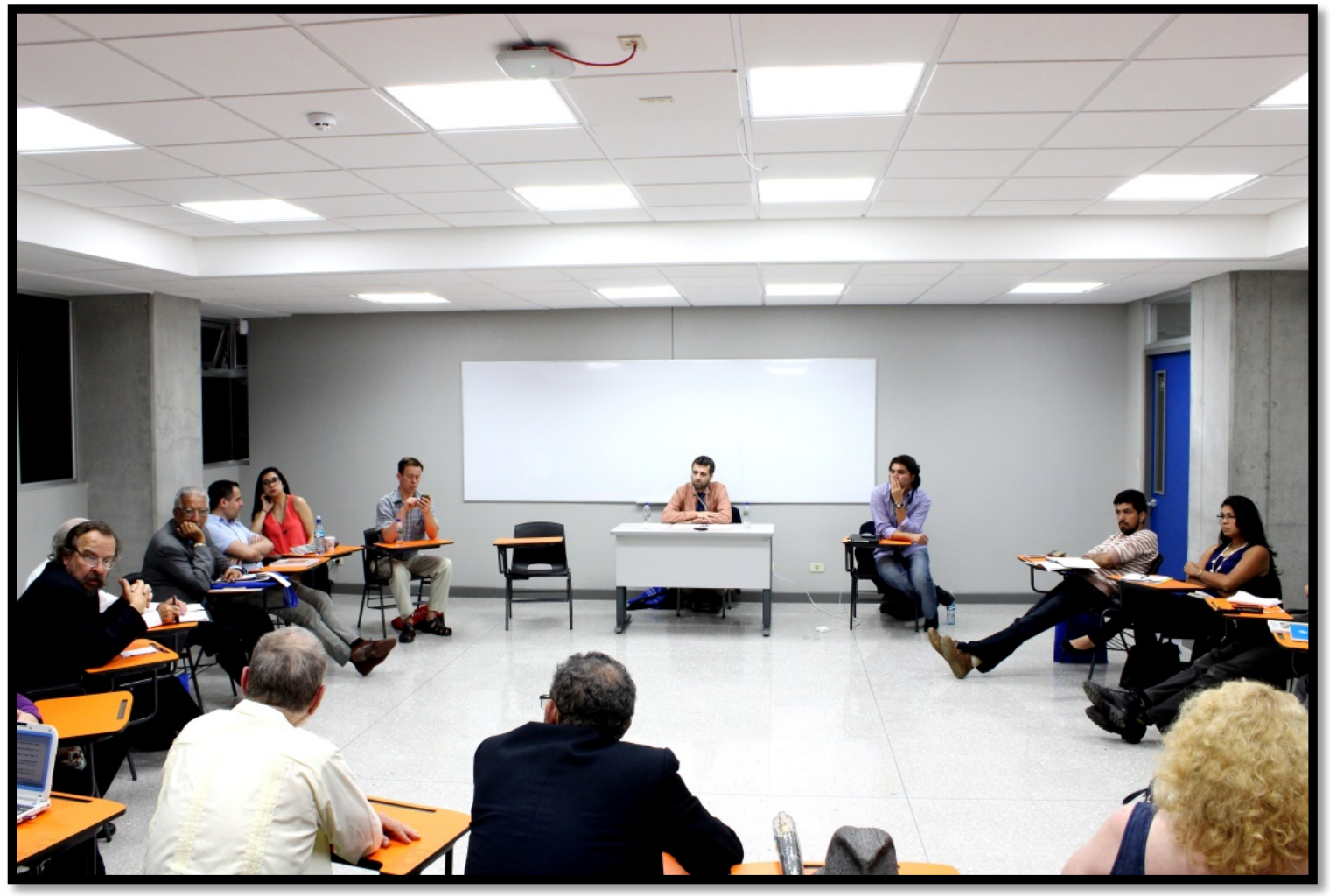

Fotos: Esteban Rodríguez-Dobles.

De esta sesión habría que destacar la discusión en torno a las fuentes para la historia de la masonería, la básica polémica de si es o no masón, y un aspecto del que habría de hacer acotación, es el debate abierto por Felipe del Solar en la Mesa Redonda: Historiografía masónica y la nueva historia de masonería latinoamericana. En la citada mesa, el historiador chileno planteó una cuestión inquietante en torno a los nacionalismos metodológicos: ¿cómo llamar a nuestros estudios nueva historia de la masonería cuando utilizamos métodos provenientes de Europa y de una Europa de mediados del siglo XX?

Aquel planteamiento restalló con fuerza, sobre todo cuando ya se habían hecho valoraciones sobre las formas de hacer historia de la masonería y las consideraciones para con sus fuentes. Creo que a más de uno la llamada de atención hecha por el Dr. Felipe del Solar nos hizo cuestionarnos sobre la novedad en nuestra rama de estudios. Ahora, con posterioridad he pensado que la novedad historiográfica está presente de otra manera.

La experiencia historiográfica latinoamericana es diferente y no debería trasponerse a la experiencia europea, ya que por ejemplo Francia tuvo décadas para desarrollar las indagaciones que la academia de los Annales hizo, a diferencia, en el caso costarricense la Historia-problema empezó a tener sus primeros frutos apenas a mediados de la década de los 70's del siglo XX. Así muchos otros campos o ramas de la historia han experimentado ciertas tradiciones y metodologías recientemente, que en otras academias lleva décadas realizándose. La novedad parece yacer en la forma en que hemos indagado hasta el 
momento en la temática de la masonería, la teosofía y el esoterismo bajo (o a pesar de) determinados condicionamientos de tipo conceptual e historiográfico propios del desarrollo de nuestras escuelas de historia.

Ahora, no por ello nos debemos quedar repitiendo fórmulas, justificando un viejo proceder y realizando comparaciones espurias, sin duda debemos construir nuestras herramientas interpretativas y pensar en esquemas nuevos para captar el fenómeno de las prácticas asociativas en el espacio geográfico latino-caribe-transatlántico e intercontinental.

Continuando con la reseña, el día 4 de noviembre de 2015 fue inaugurado oficialmente el IV Simposio Internacional de Historia de la Masonería y los Movimientos Asociativos Latinoamericanos y Caribeños: Prácticas asociativas y Modernidad, siglos $X V I I I-X X I$. Las actividades dieron inicio con una mesa que ofreció una serie de comunicaciones que consideraron la variable étnica en los asociacionismos modernos. Estuvo a cargo de la estudiante de historia Fernanda Gutiérrez, el historiador costarricense Ricardo Martínez y el historiador franco-argentino Dévrig Mólles.

Más que respuestas, las preguntas que plantearon fueron de lo más interesante; en la intervención de Mólles mediante su estudio de la migración rumana, checa y griega a Argentina planteó la existencia de logias Europeas extra-territoriales y a las mismas como sociedades de apoyo a quienes migraban y se pregunta sobre cuáles son las sensibilidades que unieron a estos grupos. Gutiérrez nos propuso ver la agenda étnica detrás de las sociedades iniciáticas del caribe costarricense, así también las logias de Oddfellows y Mechanics fungieron como espacios de integración para la creación de una conciencia étnica. Luego Martínez ofreció una perspectiva desde la Global History que le ha permitido explorar el papel de la forma asociativa de la masonería en los procesos imperialistas en África y Asia, sus interesantes ejemplos lo llevaron a preguntarse con respecto a la masonería: ¿Es un fenómeno netamente europeo? ¿Será lo exógeno (lo que está fuera de las logias) lo que modela a las logias y sus prácticas? Claramente estos estudios nos indican que las prácticas asociativas masónicas e iniciáticas traspasan los espacios nacionales, entendiéndose que la masonería(s) es un constructo social.

Luego de la mesa, se procedió a la inauguración oficial, con los discursos de las autoridades universitarias y el Gran Maestro de la Gran Logia de Costa Rica, Ronaldo Hirsch, que a su vez es profesor retirado de la UCR. El rector de la universidad, Henning Jensen Pennington citó el Fausto de Goethe para decir que la verdad es una antorcha que ilumina pero que también puede quemar, sentencia arrolladora ante un campo que empieza a extenderse, renovarse y abrirse un espacio en la academia costarricense.

Como fue anunciado, se procedió a la firma de un convenio de cooperación entre la UCR y la Gran Logia de Costa Rica, con el propósito de incentivar las labores de investigación. Este convenio es un precedente de mucha importancia pues permite tener acceso más abierto al acervo documental y los materiales museográficos con los que cuenta la Logia en cuestión. 
Imágenes 5 y 6

Acto inaugural y firma de Convenio.

Auditorio Ciudad de la Investigación: Universidad de Costa Rica
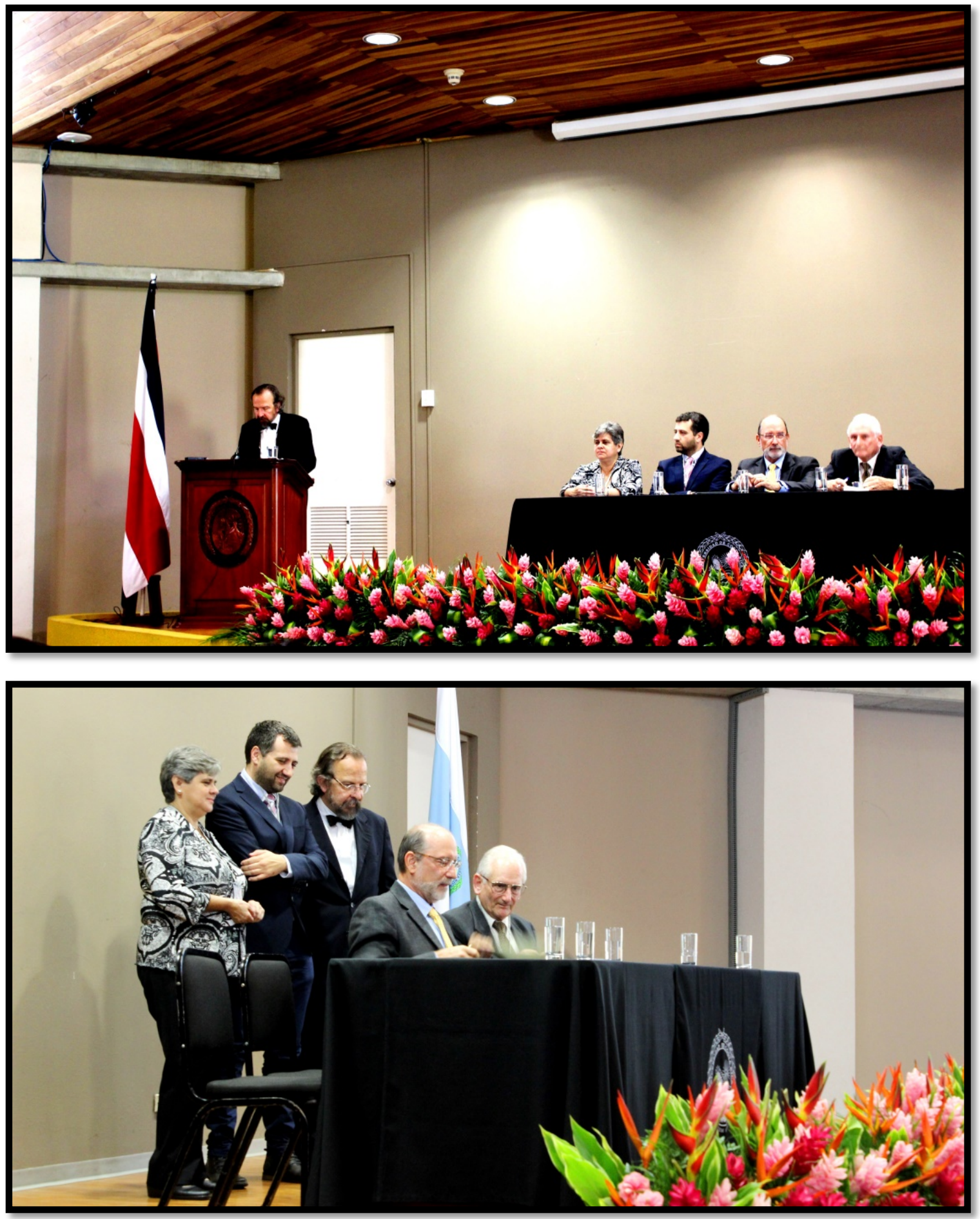

Fotos: Esteban Rodríguez-Dobles. 
Posteriormente en la conferencia inaugural impartida por el experto internacional, Dr. José Antonio Ferrer Benimelli, el expositor buscó dilucidar sobre las aportaciones al tema de la relación Iglesia y Masonería desde la Revolución Francesa, considerándola una veta rica para los estudios históricos. Su sentido discurso de alguna manera me hizo pensar en la vida que ha llevado el maestro Ferrer, pues precisamente se ha conducido entre estos dos mundos el de la Iglesia y el de la Masonería. No pretendo ser biógrafo o cosa por el estilo, solamente se trata de mi apreciación. Pero también quiero denotar que el abordaje del Dr. Ferrer parte del estudio de los masones y la masonería desde la esfera de la conflictividad.

Imagen 7

Dr. José Antonio Ferrer Benimeli, Conferencia inaugural: Masonería e Iglesia Católica. Un problema sin resolver. Auditorio de la Ciudad de la Investigación, Universidad de Costa Rica

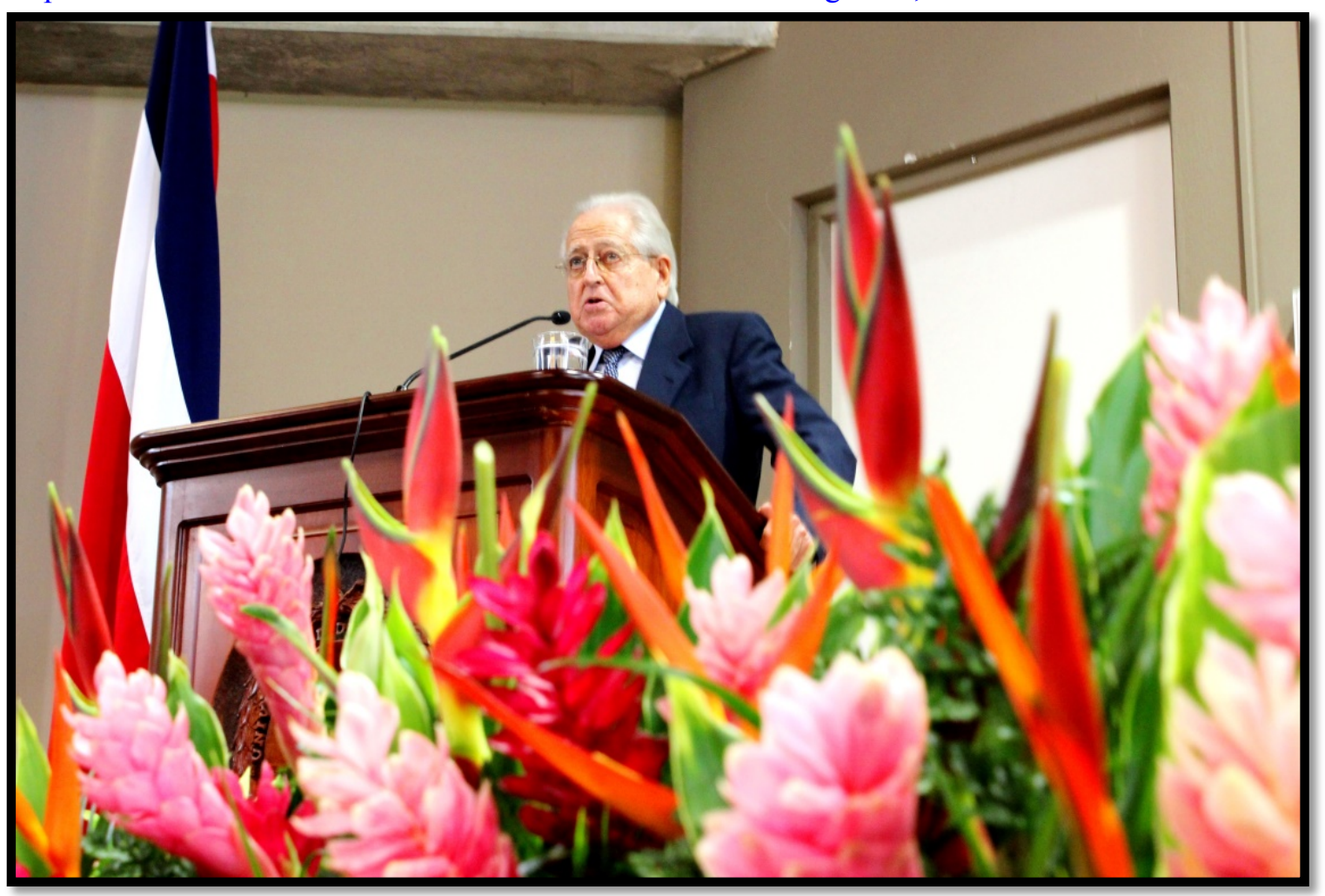

Foto: Esteban Rodríguez-Dobles.

Por la tarde tuvieron espacio varias mesas bajo el debate: Masonería, Revolución y República. Dando lugar a diversas comunicaciones cuyo marco fue precisamente el de diversos conflictos. Quizá sean este conjunto de comunicaciones las que mejor se prestan para visibilizar lo que mencioné al inicio, sobre el conflicto como cantera documental e hilo conductor en el relato histórico. 
Sin duda que el periodo de la historia moderna y contemporánea tiene un curso bajo el signo de la revuelta, la revolución, las guerras civiles, guerras independentistas, guerras mundiales. Quizá por eso Marx y Engels quisieron ver en la lucha de clases el motor de la historia. Entonces, ¿cómo hacer una historia de la masonería sin valerse del conflicto? ¿es el conflicto y la polémica el único recurso para circunscribir la historia de la masonería en la historia contemporánea?

Las comunicaciones en las mesas del día viernes 6 de noviembre, brindaron alternativas de estudio, como son los trabajos de María Zozaya, Leonardo Santamaría, Felipe Debasa-Navalpotro, Sylvia Hottinger, y Emmanuel Mora entre otros, que centran su atención propiamente en las prácticas, las artes, la arquitectura y en suma en los aspectos de la sociabilidad que menos tienen que ver con conflictividad y más apuntan sus preguntas en dirección a las formas de agrupamiento y simbolismos que encierran algunas obras, como es el caso de Chopin expuesto e interpretado magistralmente por Roberto E. Vargas Dengo. Fuera de sus metodologías, cada una distinta, las agrupo por no recurrir a la variable del conflicto, pese a algunas especulaciones conspirativas en la lectura de Hottinger-Craig.

A esto, tendría que sumarse las perspectivas dadas por el costarricense José Ricardo Chaves (UNAM) en torno a la Literatura, los aportes de Guillermo de los Reyes (Universidad de Houston) sobre la temática del género, la Literatura y la masonería. El coloquio desarrollado por estos dos especialistas, muestra un trayecto alternativo dentro de las fuentes para la historia del esoterismo y la masonería. Lo muy interesante del caso de José Ricardo, es que ha logrado desarrollar un estudio de la rara y compleja obra literaria de José Basileo Acuña, pero además en su labor como literato galardonado y consolidado ha desarrollado una obra literaria sin parangón, paradójicamente también por su rareza. La trilogía compuesta por sus novelas más recientes como es el caso de Faustófeles o la maravillosa novela Espectros de Nueva York, en ésta última recrea a través de una experiencia de investigación del narrador, los años neoyorquinos en que Olcott y Blavatsky se conocieron. En lo personal el narrador me hizo recordar algo del estilo gonzo de los mejores años de Hunter Thompson; los pasillos del hotel donde se hospedó H. P. Blavatsky están maravillosamente descritos.

Alguna vez conversando con el también escritor costarricense Carlos Cortés (quien es amigo de crianza de José Ricardo) sobre las memorias de Sidney Field Povedano que le había compartido, me dijo que él miraba estas fuentes y aquello le parecía insólito, miraba una sociedad mucho más curiosa y abierta. Yo le respondí que la realidad nos excede, y le hice saber que para mí, José Ricardo podría estar creando un nuevo estilo en la narrativa latinoamericana, sin pensarlo mucho le dije que era una especie de retro-ficción del esoterismo. Ahora, no solo me parece un nuevo estilo, sino una alternativa más para la exploración de los episodios del pasado, en ocasiones alguna literatura suele decir con mayor facilidad ciertas verdades que el historiador puro no vislumbra. 
Por otra parte, a lo largo de los días, las conferencias impartidas evidenciaron esta tendencia a favorecer el estudio del conflicto. Ya sea en Cuba, en Chile o España, la pugna por el poder palpita en los episodios tejidos por los historiadores de la masonería.

Algo tiene ésta historia cuyo objeto de estudio son las sociabilidades esotéricas, masónicas o teosóficas, y es que, todos parecen los episodios menos conocidos, todos parecen haber logrado des-encriptar algún indicio que no se conocía, no obstante, tendríamos que preguntarnos por las razones que hacen de esa sorpresa, una constante en las personas del pleno siglo XXI.

\section{Imágenes 8 y 9}

Der-izq: José Ricardo Cháves, Francisco Rodríguez, Ricardo Martínez e Yván Pozuelo. En la siguiente, el Dr. Eduardo Madrigal atento a pasar la página de la partitura, Vargas Dengo ejecuta Chopin

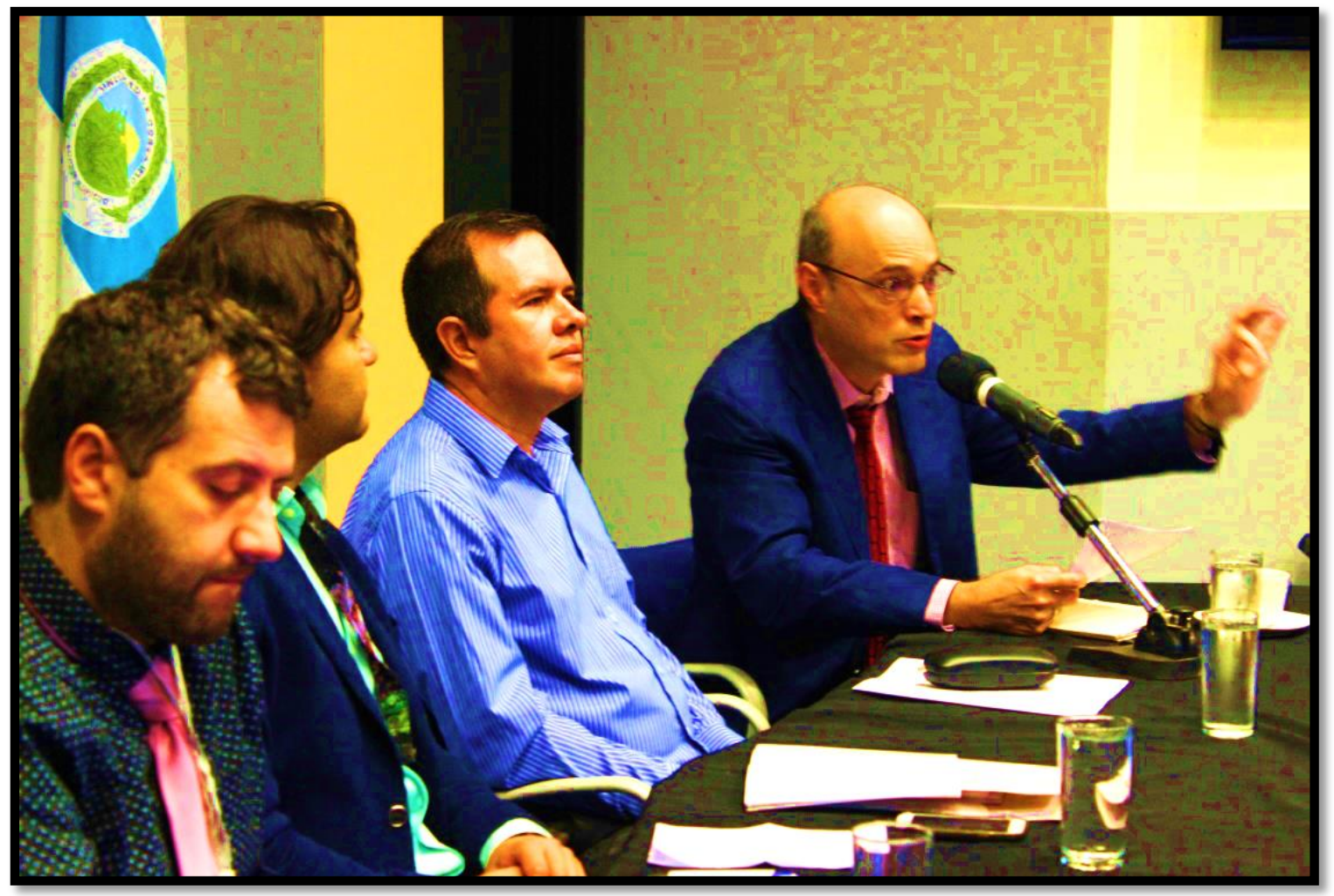




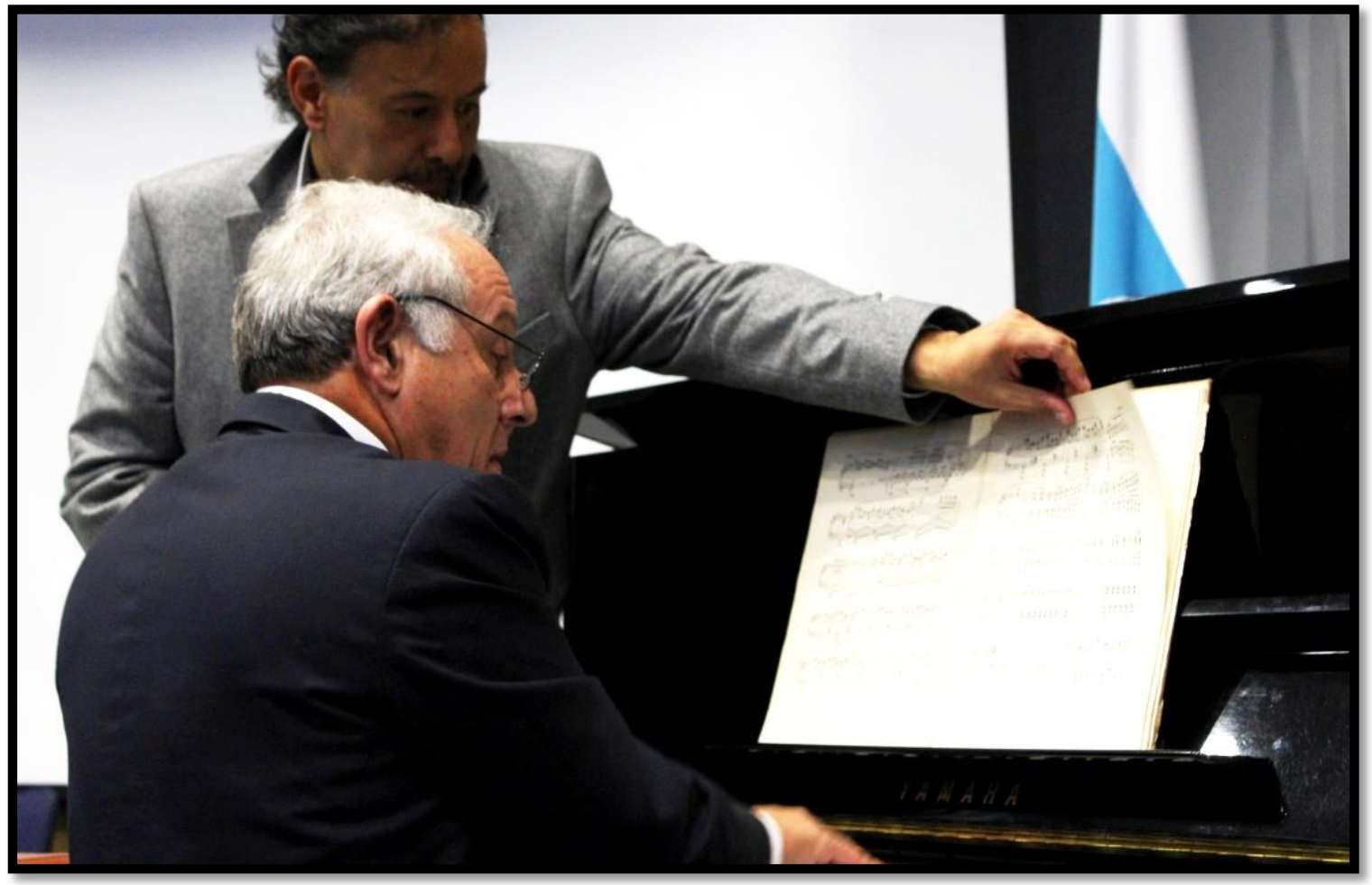

Fotos: Esteban Rodríguez-Dobles.

Finalmente desarrollamos una reunión para la conformación de una Red Académica Internacional, idea que tuvo buena acogida y fue acompañada con la propuesta de una serie de países como posibles sedes del V Simposio. Con el pasar de los meses la Red da sus primeros pasos, y desde Costa Rica se sigue trabajando para sacar pronto una serie de publicaciones en torno a la temática, así como la publicación de las actas del Simposio efectuado en la UCR.

Queda pendientes algunas tareas que pueden irse cumpliendo como la incorporación de trabajos audiovisuales, hacer un esfuerzo por enriquecer las bibliotecas de los países anfitriones y donar algunos de los ejemplares de nuestros textos para continuar extendiendo el conocimiento sobre los estudios que realizamos, la constitución de una sede física y académica de un Centro de Investigaciones de Historia de Masonería en Latinoamérica y el Caribe mediante la Red Internacional. Así parece que estamos en el inicio de un buen momento en la consolidación de esfuerzos investigativos y de proyección del quehacer de este grupo de académicos. 
Imagen 10

Dr. Miguel Guzmán-Stein, Coordinador General.

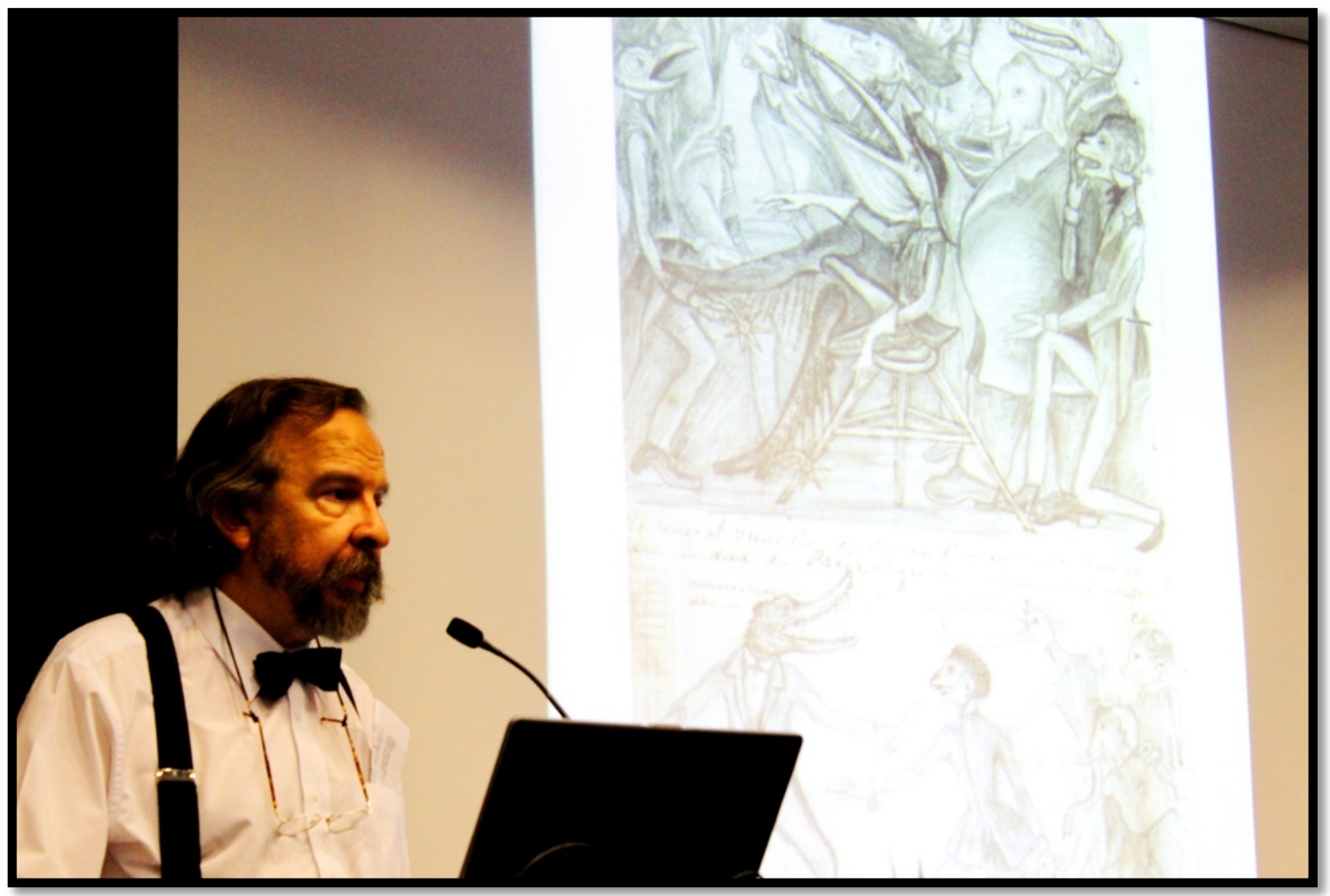

Foto: Esteban Rodríguez-Dobles 
Imagen 11

Asistencia a la Conferencia de Dr. Yván Pozuelo, Auditorio del LANAMME, UCR.

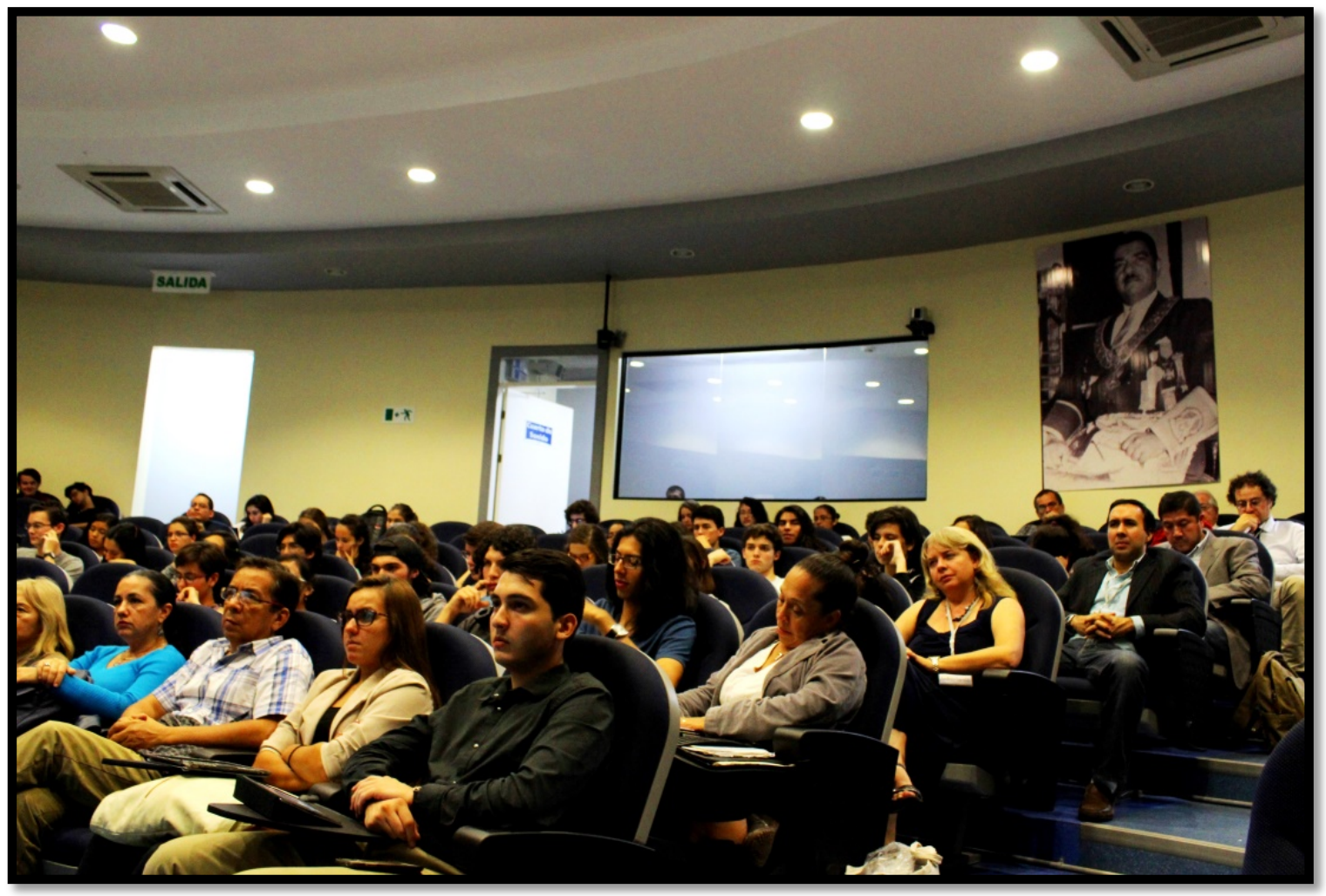

Foto: Esteban Rodríguez-Dobles 


\section{Anexo \\ Programa IV Simposio Internacional de Historia de la Masonería y los Movimientos Asociativos Latinoamericanos y Caribeños}

\section{ACTIVIDADES PRE-SIMPOSIO}

\section{DÍA 2 DE NOVIEMBRE, LUNES}

09:00-12:00 horas

I SESIÓN Seminario: Derivaciones del Esoterismo europeo-occidental de los siglos XVIII-XIX hacia Latinoamérica. Ejes principales de investigación, debates, problemas actuales.

Impartido por Juan Pablo Bubello (Universidad de Buenos Aires, Argentina).

Director del Centro de Estudios sobre el Esoterismo Occidental/UNASUR.

Lugar: Auditorio de la Biblioteca de Ciencias de la Salud.

\section{DÍA 3 DE NOVIEMBRE, MARTES}

09:00-12:00 horas

I SESIÓN Taller: Prosopografía, redes de sociabilidad y cultura asociativa en los siglos XVIII y XIX.

Impartido por Eduardo Madrigal Muñoz (Universidad de Costa Rica).

Lugar: Aula 206. Edificio de Ciencias Sociales.

\section{3:00-15:45 horas}

II SESIÓN Seminario: Derivaciones del Esoterismo europeo-occidental de los siglos XVIII-XIX hacia Latinoamérica. Ejes principales de investigación, debates, problemas actuales.

Impartido por Juan Pablo Bubello (Universidad de Buenos Aires, Argentina).

Director del Centro de Estudios sobre el Esoterismo Occidental/UNASUR.

Lugar: Auditorio de la Biblioteca de Ciencias de la Salud.

\section{6:30-18:00 horas}

Coloquio con jóvenes investigadores:

Presenta y modera: José Antonio Ferrer Benimeli (Universidad de Zaragoza, España).

Eduardo Torres-Cuevas (Universidad de La Habana, Cuba).

Yván Pozuelo Andrés (Universidad de Oviedo, España).

Dévrig Mollés (Université de Strasbourg, Francia).

Felipe del Solar (Universidad ARCIS, Santiago de Chile).

Lugar: Aula 206, Edificio de Ciencias Sociales.

\section{8:15-19:30 horas}

Mesa redonda: Historiografía masónica y la nueva Historia de la Masonería Latinoamericana Modera: Yván Pozuelo Andrés (Universidad de Oviedo, España).

Dévrig Mollés (Université de Strasbourg, Francia).

Felipe del Solar (Universidad ARCIS, Santiago de Chile).

Ricardo Martínez Esquivel (Universidad de Costa Rica). 
Miguel Guzmán-Stein (Universidad de Costa Rica).

Lugar: Aula 206, Edificio de Ciencias Sociales.

\section{DÍA 4 DE NOVIEMBRE, MIÉRCOLES}

\section{PRIMERA SESIÓN}

\section{8:30-09:45 horas}

Comunicaciones y ponencias. Debate.

La variable étnica en los asociacionismos modernos

Moderador y comentarista: Esteban Rodríguez Dobles (Universidad de Costa Rica)

1. Richard Salazar (Universidad Internacional del Ecuador), Migración y formas asociativas. Asociaciones y casas de inmigrantes. Formas de inserción, identidad y sociabilidad. Migración y masonería.

2. Karo Moret Miranda (Universitat Pompeu Fabra, España), Quintín Banderas, negro, cubano y masón. Destino manifiesto del afrodescendiente en la Cuba de los inicios del siglo XX.

3. Fernanda Gutiérrez Arrieta (Universidad de Costa Rica), La Sociedad Teosófica y las sociedades fraternales iniciáticas caribeñas: percepciones y discursos sobre la cuestión étnica en Costa Rica durante la primera mitad del siglo XX.

4. Ricardo Martínez Esquivel (Universidad de Costa Rica), Historia Global y Masonerías: Modernidad, sociabilidad e imperialismos entre Asia y África.

5. Dévrig Mollés (Université de Strasbourg, Francia), Guerra fría, masonería y exilio rumano: notas preliminares en torno a la logia Sol de Rumania (Buenos Aires, 1952-1958).

6. Roger Burt (Universidad de Exeter, Reino Unido), "Wherever Dispersed". The Travelling Mason in the Nineteenth Century.

\section{0:00-12:00 horas}

\section{Inauguración del Simposio}

Participan:

- Rector de la Universidad de Costa Rica, Henning Jensen Pennington.

- Vicerrectora de Investigación, Alice Pérez Sánchez.

- Directora de la Escuela de Estudios Generales, Ana Delia Ramírez Calderón.

- Gran Maestro de la Gran Logia de Costa Rica, Ronaldo Hirsch Kreibel.

- Coordinador General del Simposio, Miguel Guzmán-Stein.

Firma del Convenio de Cooperación entre la Universidad de Costa Rica y la Gran Logia de Costa Rica.

Conferencia Inaugural a cargo de José Antonio Ferrer Benimeli (Presidente de Honor del Centro de Estudios Históricos de la Masonería Española (CEHME) de la Universidad de Zaragoza): Masonería e Iglesia Católica. Un problema sin resolver. 


\section{SEGUNDA SESIÓN}

14:00-16:00 horas

Comunicaciones y ponencias. Debate.

Masonería, Revolución y República

Moderador y comentarista: Yván Pozuelo Andrés (Universidad de Oviedo, España)

\section{Mesa 1}

1. Jorge Luis Rodríguez Basora (Universidad Autónoma de Yucatán, México), Exilio y federalismo en el Golfo. Patriotas mexicanos y los primeros acercamientos entre las provincias rebeldes de Yucatán y Texas, 1840.

2. Guillermo de los Reyes Heredia (University of Houston, Estados Unidos), La presencia masónica en el México postrevolucionario: ¿Ocaso o transformación?

3. Valeria Aguiar Bobet (Universidad Jaume I, España), Redes epistolares entre la masonería de Marruecos y la Americana durante la II República Española.

4. Tomás Federico Arias Castro (Universidad de Costa Rica), La masonería en la Revolución Mexicana. La relación entre el presidente mexicano Francisco I. Madero González y el intelectual costarricense Rogelio Fernández Güell.

\section{Mesa 2}

1. Fernanda Santos (Universidade Federal do Espírito Santo, Brasil), A maçonaria no Brasil da pré-independência.

2. Eduardo Torres-Cuevas (Universidad de La Habana, Cuba), Las logias masónicas en la independencia de Cuba.

3. Anastassia Espinel Souares (Universidad Industrial de Santander UIS, Colombia), Los decembristas, los orígenes de la masonería rusa.

\section{6:30-18:30 horas}

\section{Coloquio sobre Literatura:}

Moderador: Juan Pablo Bubello (Universidad de Buenos Aires, Argentina).

Guillermo de los Reyes Heredia (University of Houston, Estados Unidos), Género, Literatura y Masonería.

José Ricardo Chaves Pacheco (Universidad Nacional Autónoma de México), Esoterismo, Literatura y Sociedad Teosófica.

\section{6:30-18:30 horas}

II SESIÓN Taller: Prosopografía, redes de sociabilidad y cultura asociativa en los siglos XVIII y XIX.

Impartido por Eduardo Madrigal Muñoz.

Lugar: Aula 206, Edificio de Ciencias Sociales.

\section{9:30-21:00 horas}

Concierto: Oratorio Ganganelli. De la Campaña de 1856 a la muerte de Tomás Guardia. (Homenaje a Francisco Calvo, fundador de la Masonería en Costa Rica). 
Música: Berny F. Siles Loaiza. Letra: M. Eduardo Monge Meza. Citas históricas: Tomás Federico Arias. Coro Aurora, del Museo Juan Santamaría (Alajuela). Orquesta Sinfónica de Paraíso, Cartago. Narrador: Gustavo Rojas. Solistas: Catalina Morales, soprano. Gabriel Fernández, tenor. Gabriel Morera, bajo.

Teatro Eugene O’Neill. Centro Cultural Costarricense-Norteamericano (Barrio Dent).

\section{DÍA 5 DE NOVIEMBRE, JUEVES}

\section{PRIMERA SESIÓN}

\section{8:30-09:45 horas}

Comunicaciones y ponencias. Debate.

\section{Política, poder y la masonería}

Moderador y comentarista: Miguel Guzmán-Stein (Universidad de Costa Rica).

1. Víctor David Hernández Fernández (Universidad de Guadalajara, México), La representación de la masonería como otredad imaginada por autoridades novohispanas del siglo XVIII, a través de dos procesos inquisitoriales.

2. Miguel Pereira (Universidad Interamericana de Puerto Rico), "Mis hermanos me reconocen como tal". Las relaciones exteriores de la Gran Logia Soberana de Libres y Aceptados Masones de Puerto Rico como elemento de afirmación de la identidad nacional puertorriqueña, 1885-1888.

3. Jorge Luis Romeu (Syracuse University, Estados Unidos), Análisis de la visión europea de las masonerías autóctonas de Cuba y Puerto Rico a finales del siglo XIX.

4. Jiddu Rojas Jiménez (Universidad Nacional, Costa Rica), Breve ensayo sobre la irradiación e influencia de la Masonería Cubana y Antillana en la construcción del concepto de Patria y Nación inclusiva en las prácticas discursivas y en las prácticas políticas de José Martí, Antonio Maceo y Flor Crombe.

5. José Antonio Ferrer Benimeli (CEHME-Universidad de Zaragoza, España), La Masonería entre la paz y la guerra. Ante el centenario de la Gran Guerra.

\section{9:45-10:45 horas}

Comunicaciones y ponencias. Debate.

\section{Asociacionismos y masonería}

Moderador y comentarista: Dévrig Mollés (Université de Strasbourg, Francia).

1. Leonardo Santamaría Montero (Universidad de Costa Rica), El Club Internacional de San José y la cultura ilustrada finisecular.

2. Eloy Enrique Reverón García (Universidad Central de Venezuela), La logia Unión № 5 de Caracas (Testimonio bibliográfico de su existencia).

3. Felipe R. Debasa-Navalpotro (Universidad Rey Juan Carlos, España), En torno a la estructura de la Confederación Masónica Interamericana CMI. 70 años de historia. 
11:00-12:00 horas

Conferencia a cargo de Eduardo Torres-Cuevas (Universidad de La Habana, Cuba), La Masonería cubana antes, durante y después de la Revolución de 1959.

\section{9:00-12:00 horas}

III SESIÓN Seminario: Derivaciones del Esoterismo europeo-occidental de los siglos XVIII-XIX hacia Latinoamérica. Ejes principales de investigación, debates, problemas actuales.

Impartido por el Juan Pablo Bubello (Universidad de Buenos Aires, Argentina). Director del Centro de Estudios sobre el Esoterismo Occidental/UNASUR.

Lugar: Auditorio de la Biblioteca de Ciencias de la Salud.

\section{SEGUNDA SESIÓN}

\section{4:00-16:00 horas}

Comunicaciones y ponencias. Debate.

\section{Sociedad Teosófica, Masonería mixta, intelectuales y esoterismo}

Moderador y comentarista: Ricardo Martínez Esquivel (Universidad de Costa Rica)

\section{Mesa 1}

1. Yván Pozuelo Andrés (Universidad de Oviedo, España), Manuel Martínez Méndez: masón, teósofo y martiano en Cienfuegos.

2. José Ricardo Chaves Pacheco (Universidad Nacional Autónoma de México), José Basileo Acuña: teósofo, masón y budista.

3. Francisco Rodríguez Cascante (Universidad de Costa Rica), De la personalidad a la individualidad: la búsqueda de la trascendencia en Rogelio Sotela.

\section{Mesa 2}

1. Jacqueline Murillo Fernández (Universidad Estatal a Distancia, Costa Rica), Apuntes para la historia de la mujer en la masonería: cien años de masonería mixta en Costa Rica.

2. Esteban Rodríguez Dobles (Universidad de Costa Rica), Enseñar con mística: El esoterismo occidental en la educación costarricense, profesores teósofos y universidad.

3. Juan Pablo Bubello (Universidad de Buenos Aires, Argentina), Los estudios históricos sobre el esoterismo en Latinoamérica: problemas, debates y principales líneas de investigación actuales y el rol del Centro de Estudios sobre el Esoterismo Occidental de la UNASUR.

\section{6:15-17:15 horas}

Conferencia a cargo de Felipe del Solar (Universidad ARCIS, Santiago de Chile), Los masones Salvador Allende y Augusto Pinochet. La Masonería chilena antes, durante y después del Golpe de Estado de 1972.

17:30-18:45 horas

Comunicaciones y ponencias. Debate. 


\section{Prensa católica y los antis}

Moderador y comentarista: Dévrig Mollés (Université de Strasbourg, Francia).

1. Jorge Enrique Salcedo Martínez (Universidad Javeriana, Bogotá, Colombia), La masonería en los documentos eclesiásticos católicos colombianos, 1908-1965.

2. Felipe del Solar Guajardo (Universidad ARCIS, Santiago de Chile), El escrito antimasónico en la crisis del Imperio Español. Entre "anti- lumières" y contrarrevolución.

3. René Antonio Chanta Martínez (Universidad Centroamericana José Simeón Cañas, El Salvador), Antilaicismo, anticomunismo y críticas a la masonería en la prensa católica salvadoreña durante el retorno del debate de la laicidad del Estado (1938-1940).

4. Jorge Barrientos Valverde (Universidad de Costa Rica), El anticomunismo en la prensa católica: discursos religiosos, violencia simbólica y pánico moral como dominación política 1948-1962.

\section{9:30 horas}

Concierto de Música Masónica.

Orquesta Sinfónica de la Universidad de Costa Rica. Director: Juan Manuel Arana.

Lugar: Salón de Actos. Edificio Metálico (Escuela Buenaventura Corrales). Frente al Parque Morazán.

19:00 horas (Actividad alternativa)

Presentación del libro de José Ricardo Chaves Pacheco, Espectros de Nueva York (San José: Editorial Costa Rica, 2015).

Lugar: Instituto Cultural de México en Costa Rica (Barrio Los Yoses).

\section{DÍA 6 DE NOVIEMBRE, VIERNES}

\section{PRIMERA SESIÓN}

\section{8:30-10:00 horas}

Comunicaciones y ponencias. Debate.

Las artes en la masonería: fotografía, música, cine y caricatura.

Moderador y comentarista: Eduardo Madrigal Muñoz (Universidad de Costa Rica).

1. Rogelio Aragón Juárez (Universidad Iberoamericana, México), Luces, cámara, masón: el breve pero significativo papel de la masonería en el cine y la T.V.

2. María Zozaya (Universidad de Évora, Portugal), Reinterpretar conjuntos de símbolos. El Ateneo de Madrid: ¿intelectual, teósofo o masón? (1835, 1884, 2015).

3. Sylvia Hottinger, (Universidad Carlos III, España), Uso de las fotografías masónicas.

4. Miguel Guzmán-Stein (Universidad de Costa Rica), La visita al Papa Pío IX por el Presbo. Francisco Calvo, fundador de la Masonería en Costa Rica. Crónica de un viaje a Europa.

5. Roberto E. Vargas Dengo (Universidad de Costa Rica), Características masónicas en la obra de Federico Chopin. 
10:15-11:15 horas

Conferencia a cargo de Yván Pozuelo Andrés (Universidad de Oviedo, España), El Movimiento Obrero y la Masonería.

\section{1:15-12:15 horas}

Reunión de investigadores participantes en el Simposio: Nuevos retos para el desarrollo de una Historia de la Francmasonería Latinoamericana. Programa de trabajo 2016-2019.

Consolidación de la Red Académica Internacional.

\section{SEGUNDA SESIÓN}

\section{4:30-16:00 horas}

Comunicaciones y ponencias. Debate.

Sociedad civil, esfera pública y masonería.

Moderador y comentarista: Eduardo Torres-Cuevas (Universidad de La Habana, Cuba).

\section{Mesa 1}

1. María Eugenia Vázquez Semadeni (University of California at Los Angeles, Estados Unidos), Masonería y cultura política republicana en México, siglo XIX.

2. Marco Antonio Flores Zavala (Universidad de Zacatecas, México), Apuntes sobre las sociabilidades masónicas en México, entre lo discreto de las logias y la intervención pública de sus asociaciones, 1869-1925.

3. Julio Martínez García (Universidad de Salamanca, España), El tratamiento de la masonería femenina a finales del siglo XIX en la prensa católica mexicana.

4. Augusto César Acioly Paz Silva (Universidade Federal de Pernambuco, Brasil), A Maçonaria e a imprensa nos anos 1930 em Pernambuco.

\section{Mesa 2}

1. Emmanuel Mora Iglesias (Universidad de Costa Rica), La logia de alemanes Eintracht № 6 del Valle de San José, Costa Rica.

2. Yván Pozuelo Andrés (Universidad de Oviedo, España) y Ricardo Martínez Esquivel (Universidad de Costa Rica, Costa Rica), Educación escolar y masonería: notas sobre su origen y desarrollo. Krausistas, positivistas y racionalistas en Costa Rica (1865-1899).

3. Ivonne Cortés (Universidad Alberto Hurtado, Santiago de Chile), Masonería y espacio público: El debate en torno de la escuela Blas Cuevas .

4. Haens Beltrán Alonso, Jency Mendoza Otero (Universidad de Cienfuegos, Cuba) y Samuel Sánchez Gálvez (Universidad Estatal de Ecuador), Relación Masonería-Educación: Análisis desde el contexto cubano.

16:15-17:15 horas

Conferencia a cargo de Dévrig Mollés (Université de Strasbourg, Francia), Latinoamérica y el sistema-mundo masónico: Elementos para una historia de la opinión pública internacional. 


\section{7:15-18:15 horas}

Presentación de libros

- José Antonio Ferrer Benimeli, Masonería, Iglesia, Revolución e Independencia (Bogotá: Editorial de la Pontificia Universidad Javeriana, 2015), presentado por Jorge Enrique Salcedo Martínez.

- Dévrig Mollés, La invención de la masonería. Revolución cultural: religión, ciencia y exilios (La Plata, Argentina: Editora de la Universidad Nacional de La Plata, 2015), presentado por Felipe del Solar Guajardo.

- Tomás Federico Arias Castro, 150 años de la Historia de la Masonería en Costa Rica (San José: Editorial Costa Rica), presentado por Miguel Guzmán-Stein.

- Marco Antonio Flores Zavala, Antes de la batalla. Referencias sobre el acontecer en la vetusta ciudad de Zacatecas (agosto de 1910-junio de 1914) (México: Conaculta, 2014), presentado por Sylvia Hottinger.

- Yván Pozuelo Andrés, La masonería en Asturias (1931-1939) (Oviedo: Universidad de Oviedo, 2012), presentado por Ricardo Martínez Esquivel.

- José Ricardo Chaves Pacheco, Espectros de Nueva York (San José: Editorial Costa Rica, 2015), presentado por Francisco Rodríguez Cascante.

19:30-20:00 horas

Acto de Clausura

Gran Logia de Costa Rica: Tenida blanca. Recepción a los participantes en el Simposio.

\section{DÍA 7 NOVIEMBRE, SÁBADO}

\section{Reunión general de investigadores.}

